Supporting Information for

\title{
A Ligand-Directed Approach to Activity-Based Sensing: Developing Palladacycle Fluorescent Probes that Enable Endogenous Carbon Monoxide Detection
}

Johannes Morstein, ${ }^{\dagger}, \|$ Denis Höfler, ${ }^{\dagger}$ Kohei Ueno, Jonah W. Jurss, ${ }^{+}, \int S$ Ryan R. Walvoord, ${ }^{\dagger, \#}$ Kevin J. Bruemmer, ${ }^{\dagger}$ Samir P. Rezgui, ${ }^{\Phi}$ Thomas F. Brewer, ${ }^{\dagger, \perp}$ Minoru Saitoe, ${ }^{\int}$ Brian W. Michel, ${ }^{*,+, \Phi}$ Christopher J. Chang ${ }^{*,+, \neq, \S}$

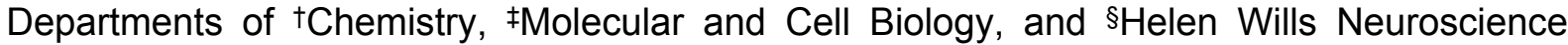
Institute, University of California, Berkeley, California 94720, United States

Tokyo Metropolitan Institute of Medical Science, Tokyo, 1568506, Japan

$\oint$ Department of Chemistry and Biochemistry, University of Denver, Denver, Colorado, 80210, United States

Table of Contents

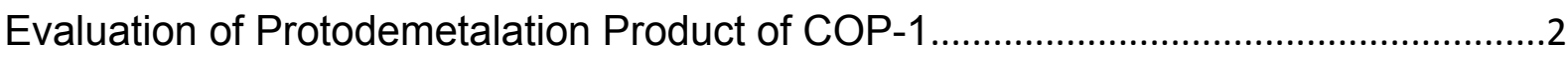

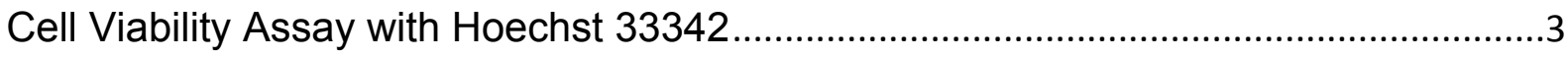

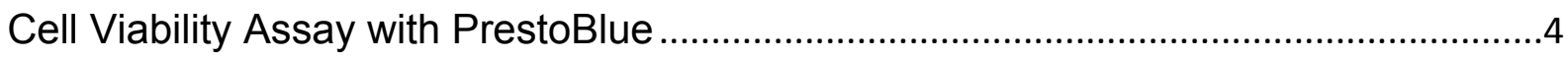

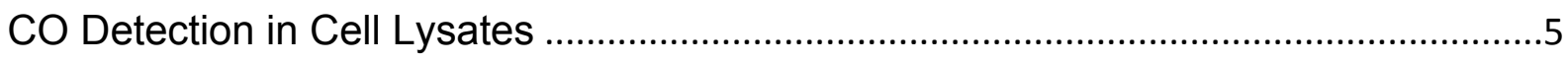

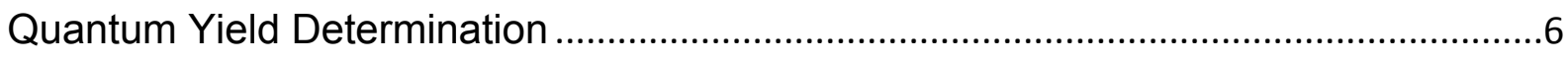

Absorption and Emission Profile of COP-3E-Py...................................................

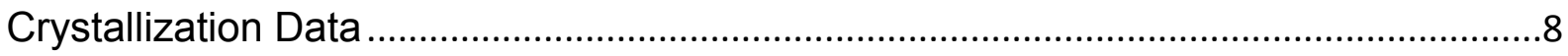

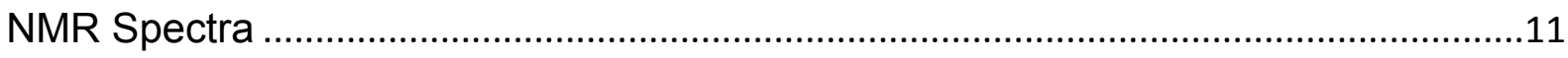

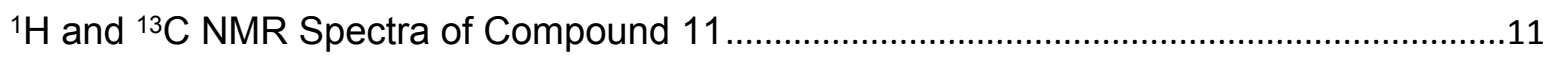

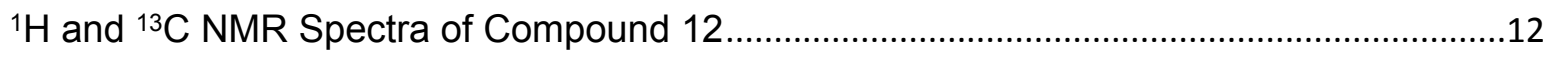

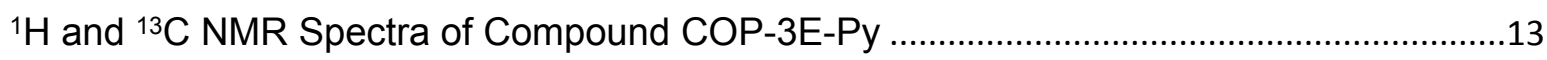

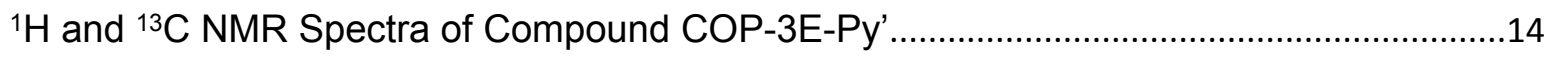

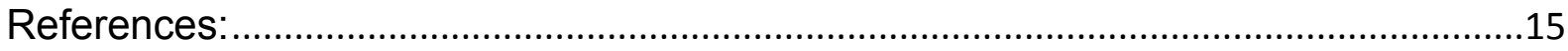




\section{Evaluation of Protodemetalation Product of COP-1}

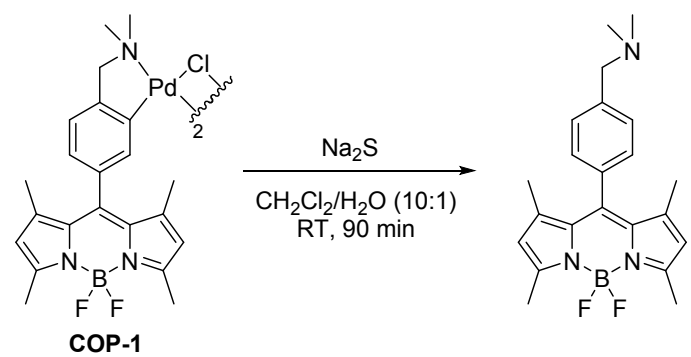

Freshly prepared COP-1 (10 mg, $9.6 \mu \mathrm{mol}, 1.0$ equiv.) was added to a scintillation vial along with $\mathrm{CH}_{2} \mathrm{Cl}_{2}(1 \mathrm{~mL})$ and $\mathrm{DI} \mathrm{H}_{2} \mathrm{O}(0.1 \mathrm{~mL}) . \mathrm{Na}_{2} \mathrm{~S}(15 \mathrm{mg}, 0.19 \mathrm{mmol}, 20$ equiv.) and a stir bar were then added, and the vial was protected from light. The reaction mixture was allowed to stir for 90 minutes at room temperature, at which point $\mathrm{CH}_{2} \mathrm{Cl}_{2}$ was removed in-vacuo. The crude solid was then dissolved in methanol, pushed through a $0.2 \mu \mathrm{m}$ filter, and subjected to LC/MS. MS $\left(\mathrm{APCl}^{+}\right) \mathrm{m} / \mathrm{z}$ : $[\mathrm{M}+\mathrm{H}]^{+}$Calculated for $\mathrm{C}_{22} \mathrm{H}_{27} \mathrm{BF}_{2} \mathrm{~N}_{3}{ }^{+}$382.2; found 382.2. [M-F] ${ }^{+}$ Calculted for $\mathrm{C}_{22} \mathrm{H}_{26} \mathrm{BFN}_{3}{ }^{+}$362.2; found 362.2.

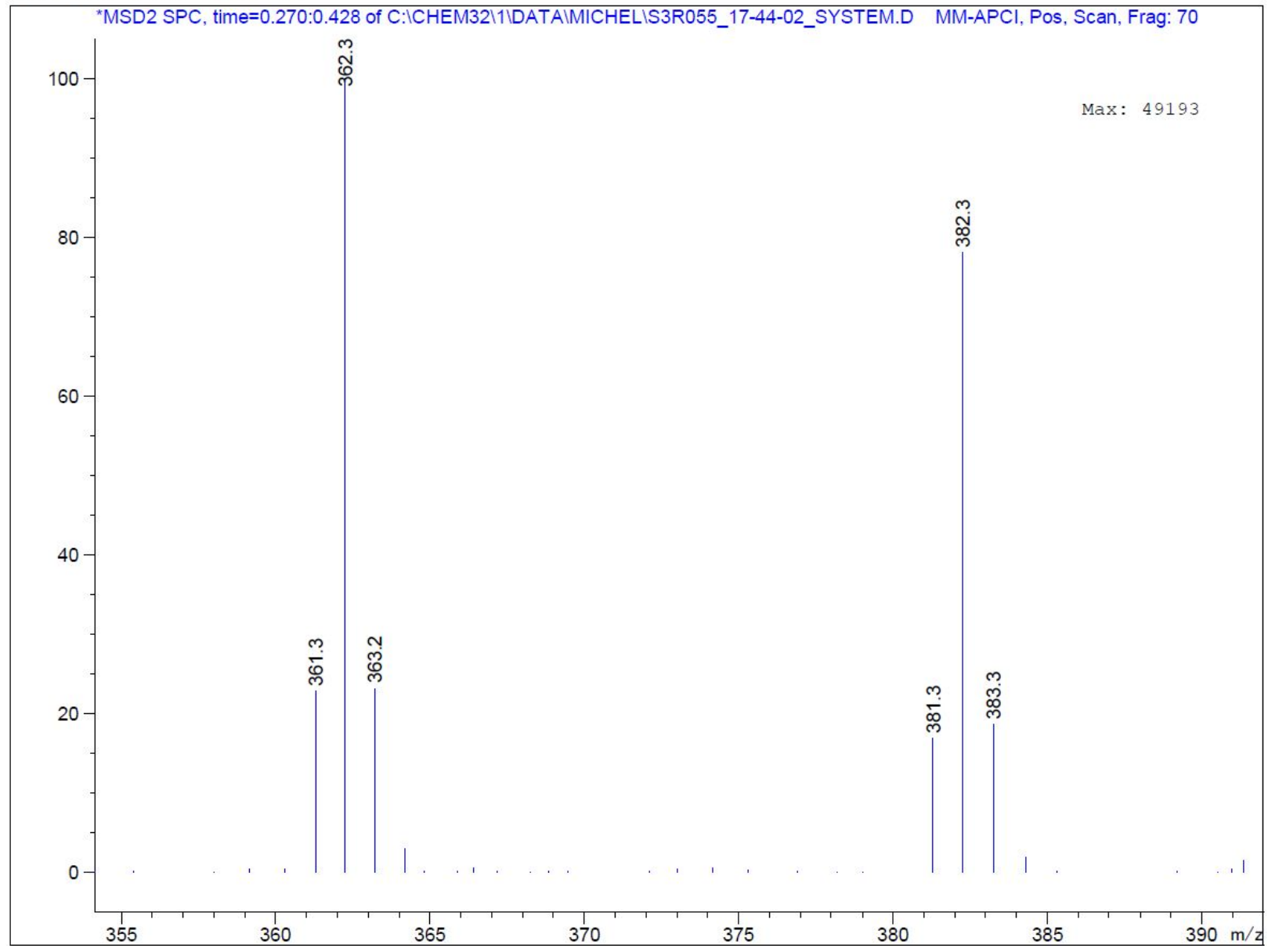

Figure S1. LCMS trace of COP-1 protodemetalation product. 


\section{Cell Viability Assay with Hoechst 33342}
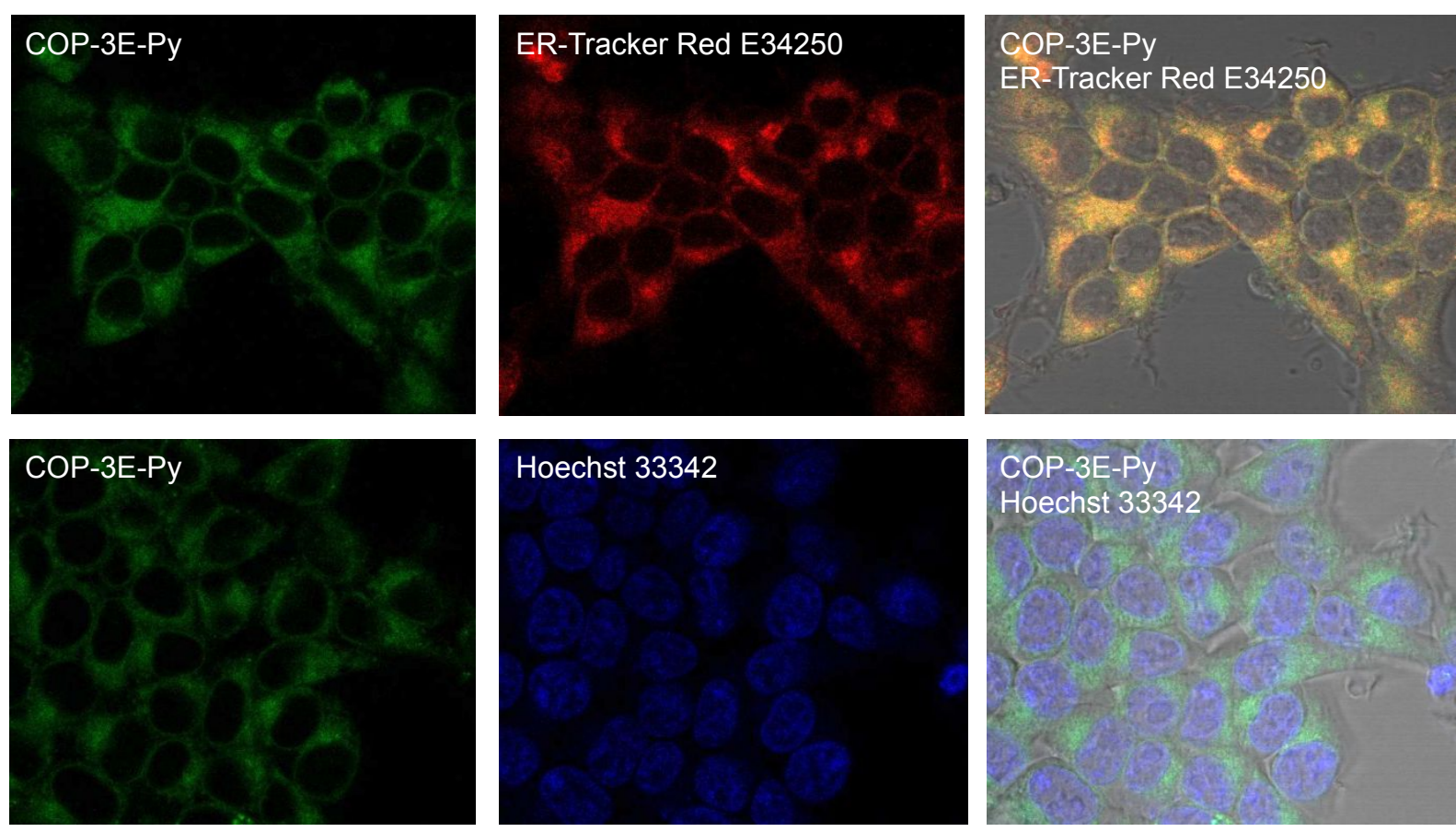

Figure S2. Colocalization experiments with ER-Tracker Red E34250 and Hoechst 33342. HEK293T cells were incubated with COP-3E-Py $(1 \mu \mathrm{M})$ for 90 min. ER-Tracker Red E34250 $(1 \mu \mathrm{M})$ or Hoechst $33342(1 \mu \mathrm{M})$ were added after $90 \mathrm{~min}$ and pictures were taken after 120 min. The ER-Tracker colocalization experiments show that COP-3E-Py targets the ER. Hoechst staining shows viable nuclei after 120 min of COP-3E-Py incubation. 


\section{Cell Viability Assay with PrestoBlue}

Cell Viability COP-3E-Py $(1 \mu \mathrm{M})$

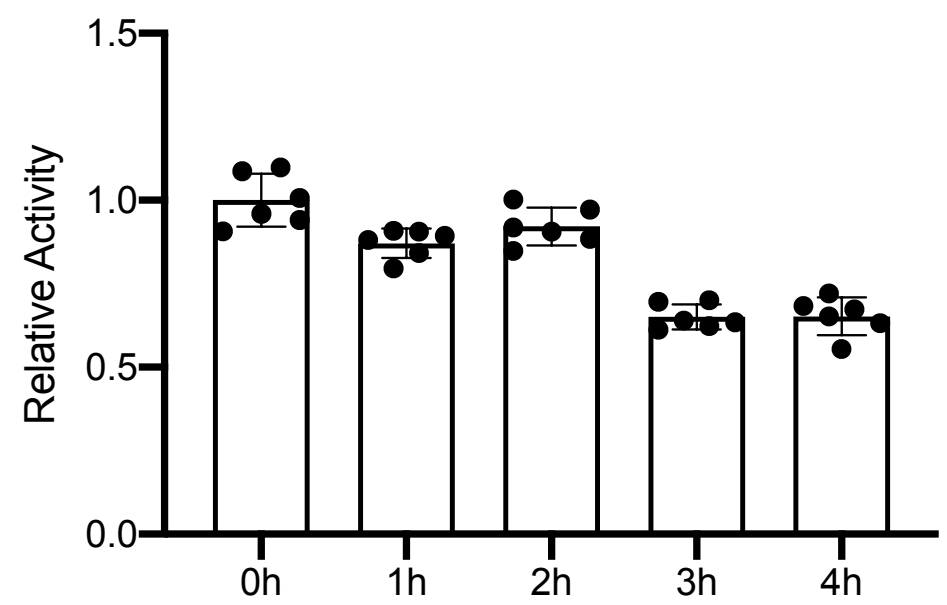

Figure S3. Viability of HEK293t cells after incubation of COP-3E-Py $(1 \mu \mathrm{M})$ for $1,2,3$, and 4 hours. DMSO vehicle or $1 \mu \mathrm{M}$ COP-3E-Py were added to cells in $100 \mu \mathrm{L} \mathrm{HBSS}$ at $37^{\circ} \mathrm{C}$ in a clear 96 well plate (Corning). Following the indicated incubation time, the cells were exchanged into $90 \mu \mathrm{L}$ fresh HBSS and $10 \mu \mathrm{L}$ PrestoBlue (ThermoFisher) was added to each well and incubated at $37^{\circ} \mathrm{C}$ for $90 \mathrm{~min}$. Fluorescence (monofilter) was read at $560 \mathrm{nM}$ excitation and $590 \mathrm{~nm}$ emission on a Synergy M2 plate reader (BioTek Instruments). 


\section{CO Detection in Cell Lysates}

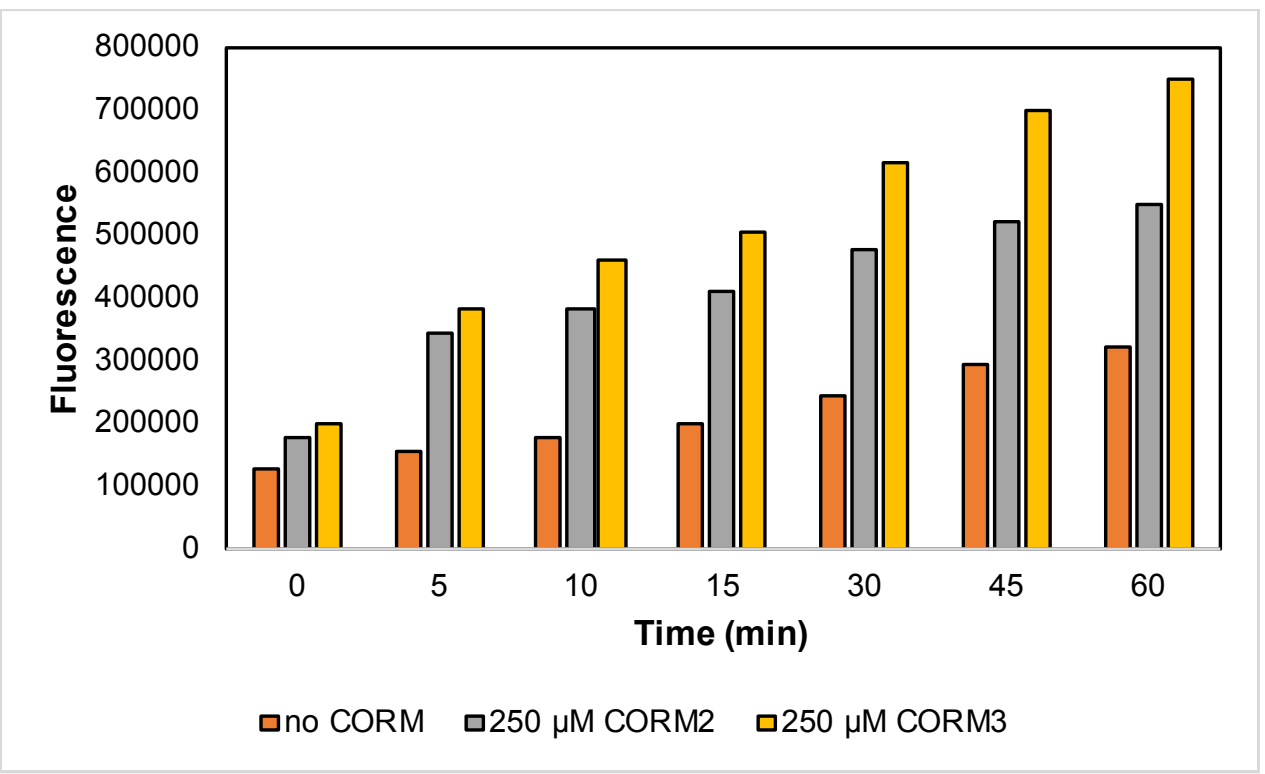

Figure S4. CO Detection in Cell Lysates. $1000 \mu \mathrm{L}$ of $1 \mathrm{mg} / \mathrm{mL}$ HeLa cell lysate in PBS was added to a cuvette and incubated with $1 \mu \mathrm{M}$ COP-3E-Py and $250 \mu \mathrm{M}$ CORM from DMSO stock solutions. Fluorescence was monitored at $515 \mathrm{~nm}$ excitation with 520-630 nm emission collection. Time points taken at before CORM, $\mathrm{t}=0,5,15,30,45$, and $60 \mathrm{~min}$. Cuvette kept at $37^{\circ} \mathrm{C}$ for the experiment. 


\section{Quantum Yield Determination}

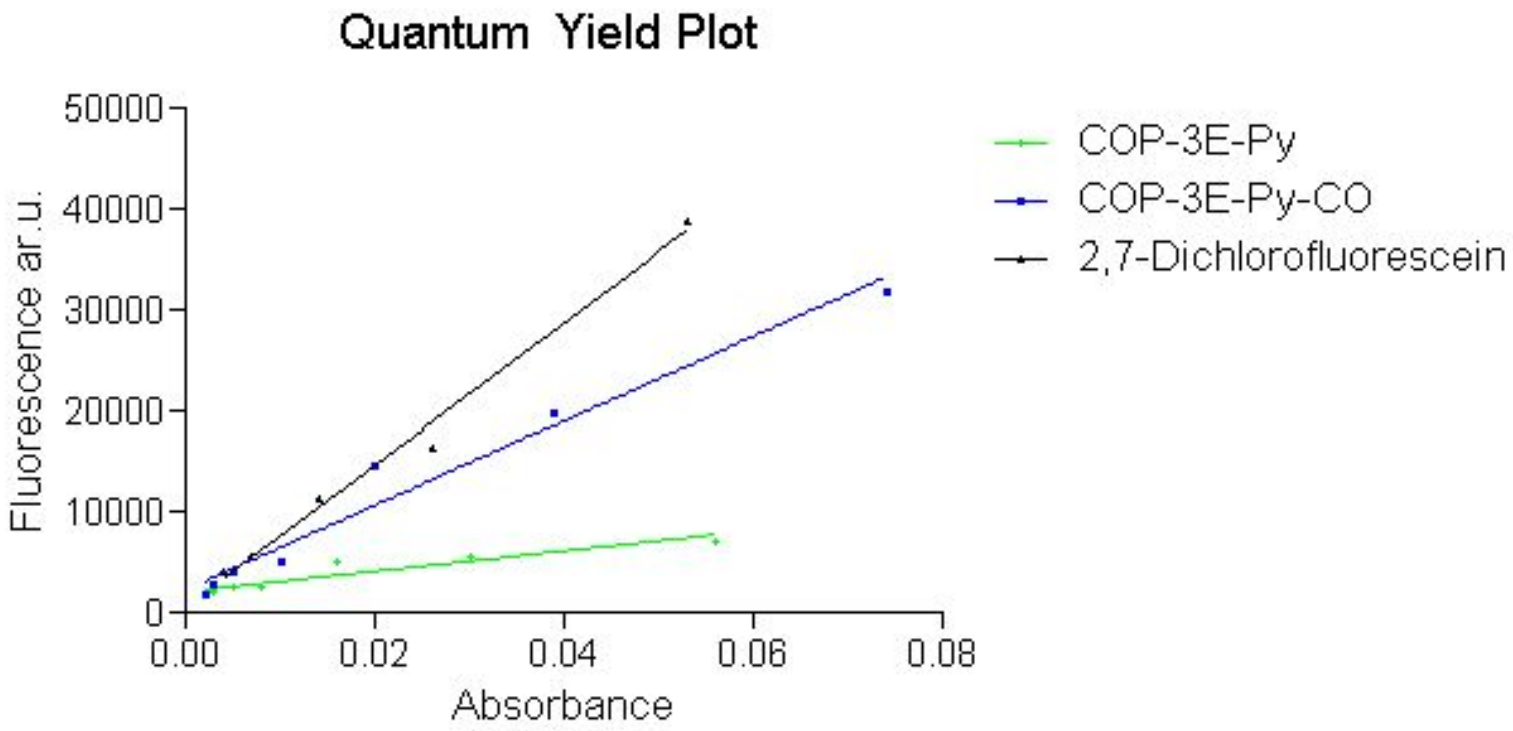

Figure S5. Relative fluorescence intensities for determining quantum yields using 2,7dichlorofluorescein as a standard. [1] 


\section{Absorption and Emission Profile of COP-3E-Py}

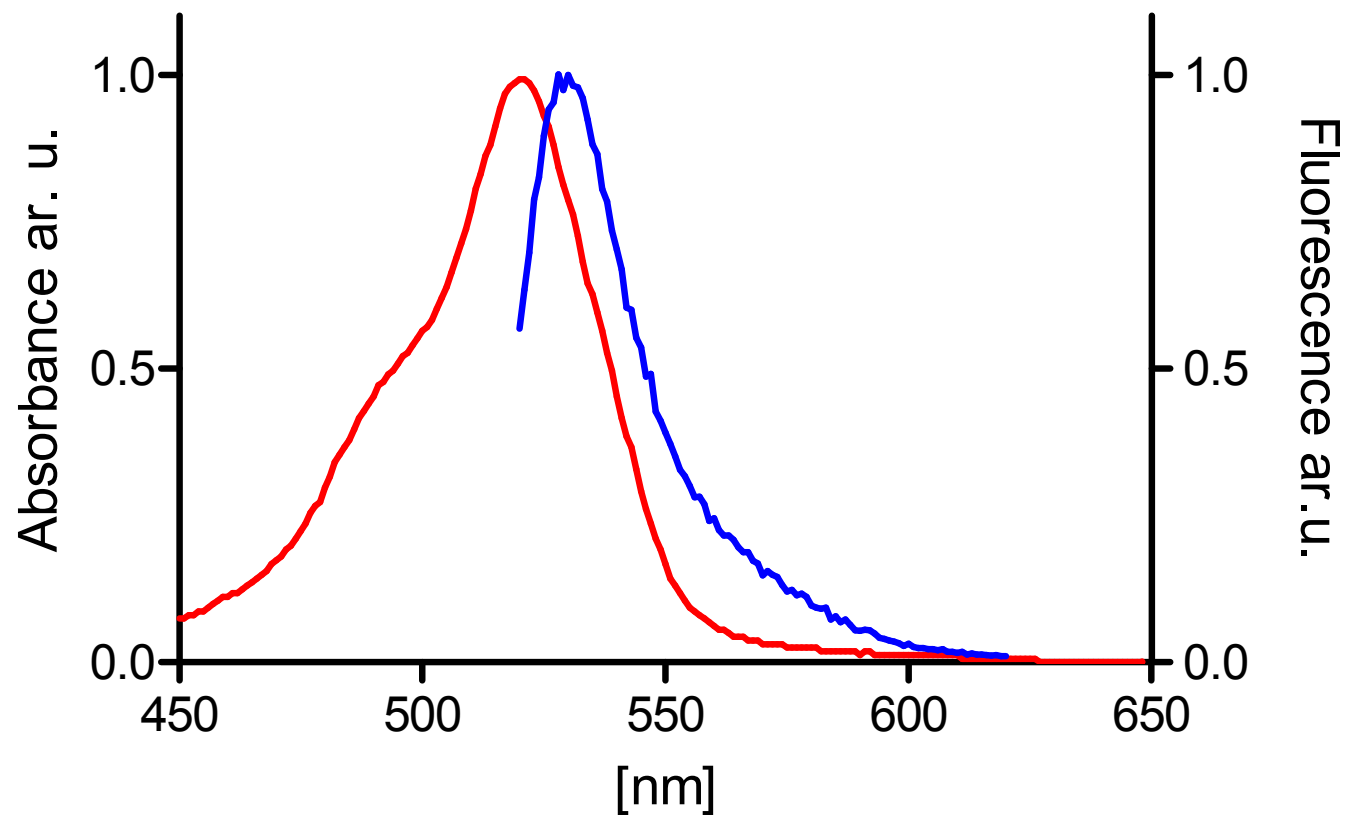

Figure S6. Absorption (red) and Emission (blue) spectra of COP-3E-Py recorded with a synergyMx plate reader (BioTek). 


\section{Crystallization Data}

Table S1. Crystallization Data for COP-1 Probes and Product

\begin{tabular}{|c|c|c|c|}
\hline & COP-1 & COP-1-Py & COP-1 \\
\hline Empirical Formula & $\mathrm{C}_{51} \mathrm{H}_{58} \mathrm{~B}_{2} \mathrm{Cl}_{2} \mathrm{~F}_{4} \mathrm{~N}_{6} \mathrm{Pd}_{2}$ & $\mathrm{C}_{27} \mathrm{H}_{30} \mathrm{BClF}_{2} \mathrm{~N}_{4} \mathrm{Pd}$ & $\mathrm{C}_{23} \mathrm{H}_{26} \mathrm{BF}_{2} \mathrm{~N}_{3} \mathrm{O}_{2}$ \\
\hline Formula Weight & $1136.35 \mathrm{~g} / \mathrm{mol}$ & $601.21 \mathrm{~g} / \mathrm{mol}$ & $425.28 \mathrm{~g} / \mathrm{mol}$ \\
\hline $\mathrm{T}(\mathrm{K})$ & $100(2)$ & $100(2)$ & $100(2)$ \\
\hline$\lambda(\AA)$ & 0.71073 & 0.71073 & 0.71073 \\
\hline Crystal System & Triclinic & Monoclinic & Triclinic \\
\hline Space Group & $P-1$ & $\mathrm{P} 2(1) / \mathrm{c}$ & $P-1$ \\
\hline$a(\AA)$ & $6.7374(6)$ & $17.1369(8)$ & 6.815 \\
\hline$b(\AA)$ & 13.1786(13) & $12.7322(6)$ & 7.825 \\
\hline$c(\AA)$ & $14.4770(12)$ & $12.0144(5)$ & $20.2310(10)$ \\
\hline$\alpha\left(^{\circ}\right)$ & $75.796(4)$ & 90 & $98.326(2)$ \\
\hline$\beta\left({ }^{\circ}\right)$ & $82.956(4)$ & $103.187(2)$ & $91.920(2)$ \\
\hline$\gamma\left({ }^{\circ}\right)$ & $78.182(4)$ & 90 & $100.133(2)$ \\
\hline $\mathrm{V}\left(\AA^{3}\right)$ & 1216.14(19) & $2552.3(2)$ & $1048.92(5)$ \\
\hline Z & 1 & 4 & 2 \\
\hline$\rho_{\text {calc }}\left(\mathrm{g} / \mathrm{cm}^{3}\right)$ & 1.552 & 1.565 & 1.347 \\
\hline$\mu\left(\mathrm{mm}^{-1}\right)$ & 0.907 & 0.871 & 0.098 \\
\hline$F(000)$ & 578 & 1224 & 448 \\
\hline$\theta$ range for data collectn & 1.46 to $25.35^{\circ}$ & 2.01 to $25.38^{\circ}$ & 2.04 to $25.39^{\circ}$ \\
\hline Index ranges & $-8 \leq h \leq 8,-15 \leq k \leq 15$ & $\begin{array}{c}-20 \leq \mathrm{h} \leq 20,-15 \leq \mathrm{k} \leq \\
15\end{array}$ & $\begin{array}{c}-8 \leq \mathrm{h} \leq 8,-9 \leq \mathrm{k} \leq \\
9,\end{array}$ \\
\hline
\end{tabular}




\begin{tabular}{|c|c|c|c|}
\hline & $-17 \leq \mathrm{I} \leq 17$ & $-13 \leq \mathrm{I} \leq 14$ & $-24 \leq \mathrm{I} \leq 24$ \\
\hline Reflections collected & 11811 & 37283 & 17611 \\
\hline Independent reflections & $4426[R($ int $)=0.0365]$ & $4684[R($ int $)=0.0212]$ & $\begin{array}{c}3866[R(\text { int })= \\
0.0412]\end{array}$ \\
\hline $\begin{array}{l}\text { Completeness to } \theta= \\
25.00^{\circ}\end{array}$ & $99.7 \%$ & $99.9 \%$ & $99.9 \%$ \\
\hline $\begin{array}{l}\text { Max. and min. } \\
\text { transmission }\end{array}$ & 0.8759 and 0.7418 & 0.8451 and 0.8451 & 0.9816 and 0.9750 \\
\hline data/restr/params & $4426 / 0 / 314$ & 4684 / 0 / 331 & $3866 / 0 / 290$ \\
\hline GOF on $F^{2}$ & 1.036 & 1.060 & 1.030 \\
\hline Final R indices $[I>2 \sigma(I)]$ & $\begin{array}{c}\mathrm{R} 1=0.0312, w R 2= \\
0.0622\end{array}$ & $\begin{array}{c}\mathrm{R} 1=0.0205, \mathrm{wR} 2= \\
0.0560\end{array}$ & $\begin{aligned} \mathrm{R} 1= & 0.0380, \mathrm{wR} 2 \\
& =0.0928\end{aligned}$ \\
\hline $\mathrm{R}$ indices (all data) & $\begin{array}{c}\mathrm{R} 1=0.0379, \mathrm{wR} 2= \\
0.0656\end{array}$ & $\begin{array}{c}\mathrm{R} 1=0.0215, \mathrm{wR} 2= \\
0.0567\end{array}$ & $\begin{aligned} \mathrm{R} 1= & 0.0453, \mathrm{wR} 2 \\
= & 0.0984\end{aligned}$ \\
\hline $\begin{array}{l}\text { Largest diff. peak and } \\
\text { hole }\left(e \AA^{-3}\right)\end{array}$ & 0.425 and -0.463 & 0.816 and -0.392 & 0.340 and -0.304 \\
\hline
\end{tabular}


Table S2. Key Bond Distances and Angles

\begin{tabular}{|c|c|c|}
\hline $\begin{array}{c}\text { Bond Distances } \\
\text { and Angles }\end{array}$ & COP-1 & COP-1-Py \\
\hline $\mathrm{Pd}-\mathrm{N}^{\mathrm{a}}$ & $2.079(2)$ & $2.0769(16)$ \\
\hline $\mathrm{Pd}-\mathrm{C}$ & $1.970(3)$ & $1.9901(18)$ \\
\hline $\mathrm{Pd}-\mathrm{Cl}^{\mathrm{b}}$ & $2.3335(7)$ & - \\
\hline $\mathrm{Pd}-\mathrm{Cl}{ }^{\mathrm{c}}$ & $2.4598(7)$ & $2.4076(5)$ \\
\hline $\mathrm{Pd}-\mathrm{N}_{\mathrm{py}}{ }^{\mathrm{d}}$ & - & $2.0421(16)$ \\
\hline $\mathrm{Cl}-\mathrm{Pd}-\mathrm{Cl}$ & $86.41(2)$ & - \\
\hline $\mathrm{C}-\mathrm{Pd}-\mathrm{N}^{\mathrm{a}}$ & $83.24(10)$ & $81.70(7)$ \\
\hline $\mathrm{Cl}-\mathrm{Pd}-\mathrm{N}_{\mathrm{py}}{ }^{\mathrm{d}}$ & - & $89.65(5)$ \\
\hline
\end{tabular}
a. $\mathrm{N}$ of amine donor
b. $\mathrm{Pd}-\mathrm{Cl}$ trans to amine donor
c. Pd-Cl bond trans to cyclometalated benzene
d. $\mathrm{N}$ of pyridine donor 


\section{NMR Spectra}

\section{${ }^{1} \mathrm{H}$ and ${ }^{13} \mathrm{C}$ NMR Spectra of Compound 11}

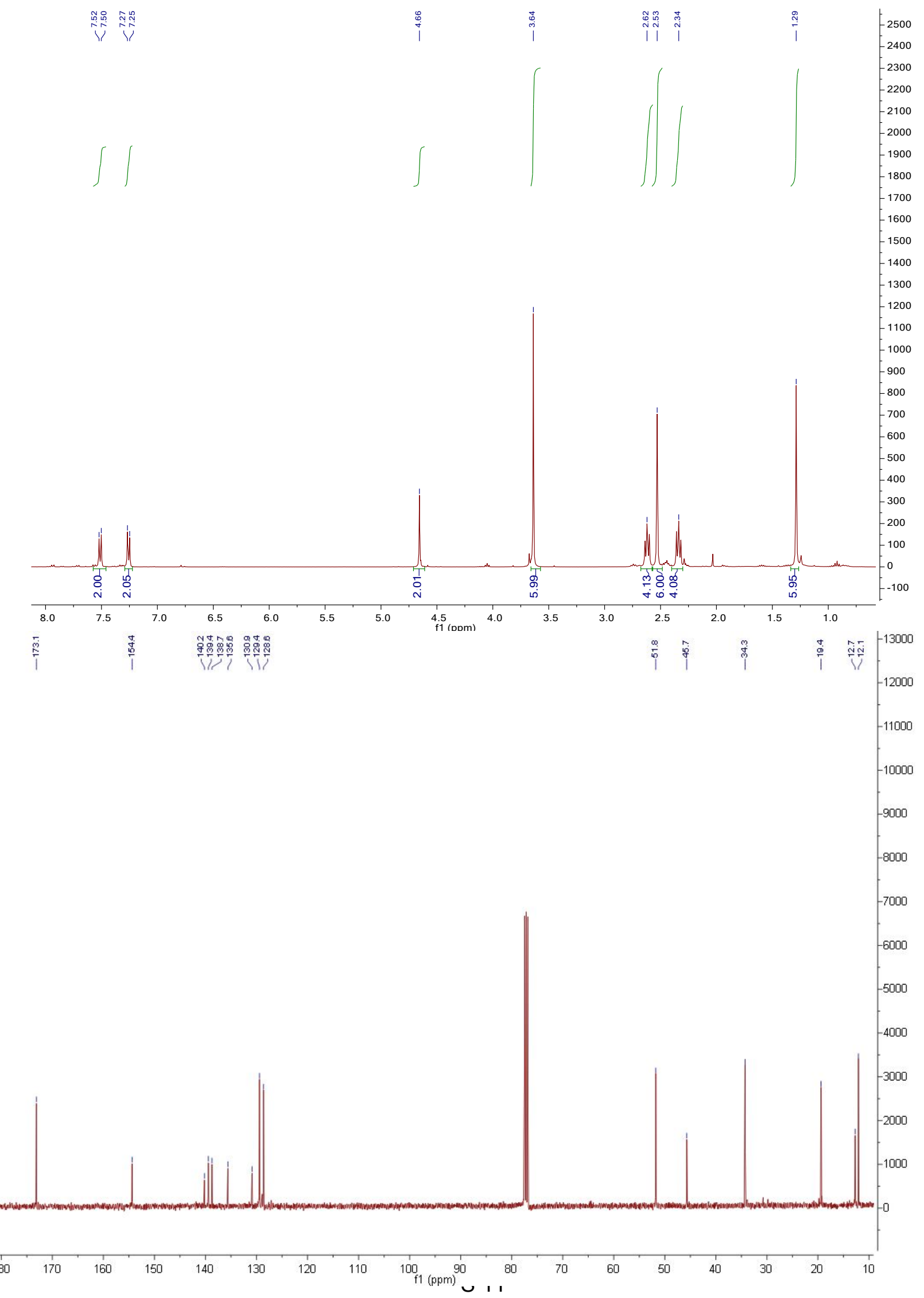


${ }^{1} \mathrm{H}$ and ${ }^{13} \mathrm{C}$ NMR Spectra of Compound 12

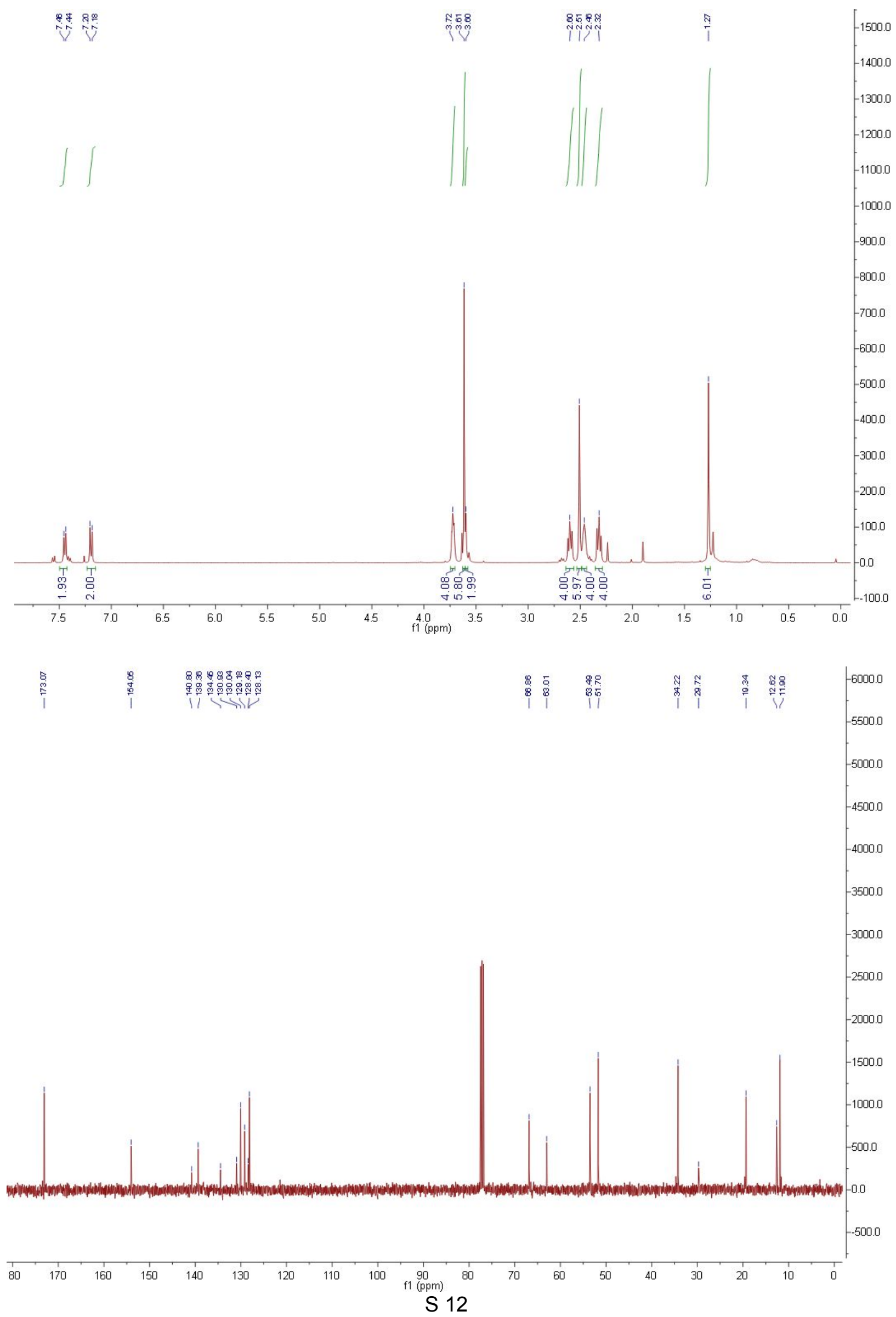




\section{${ }^{1} \mathrm{H}$ and ${ }^{13} \mathrm{C}$ NMR Spectra of Compound COP-3E-Py}
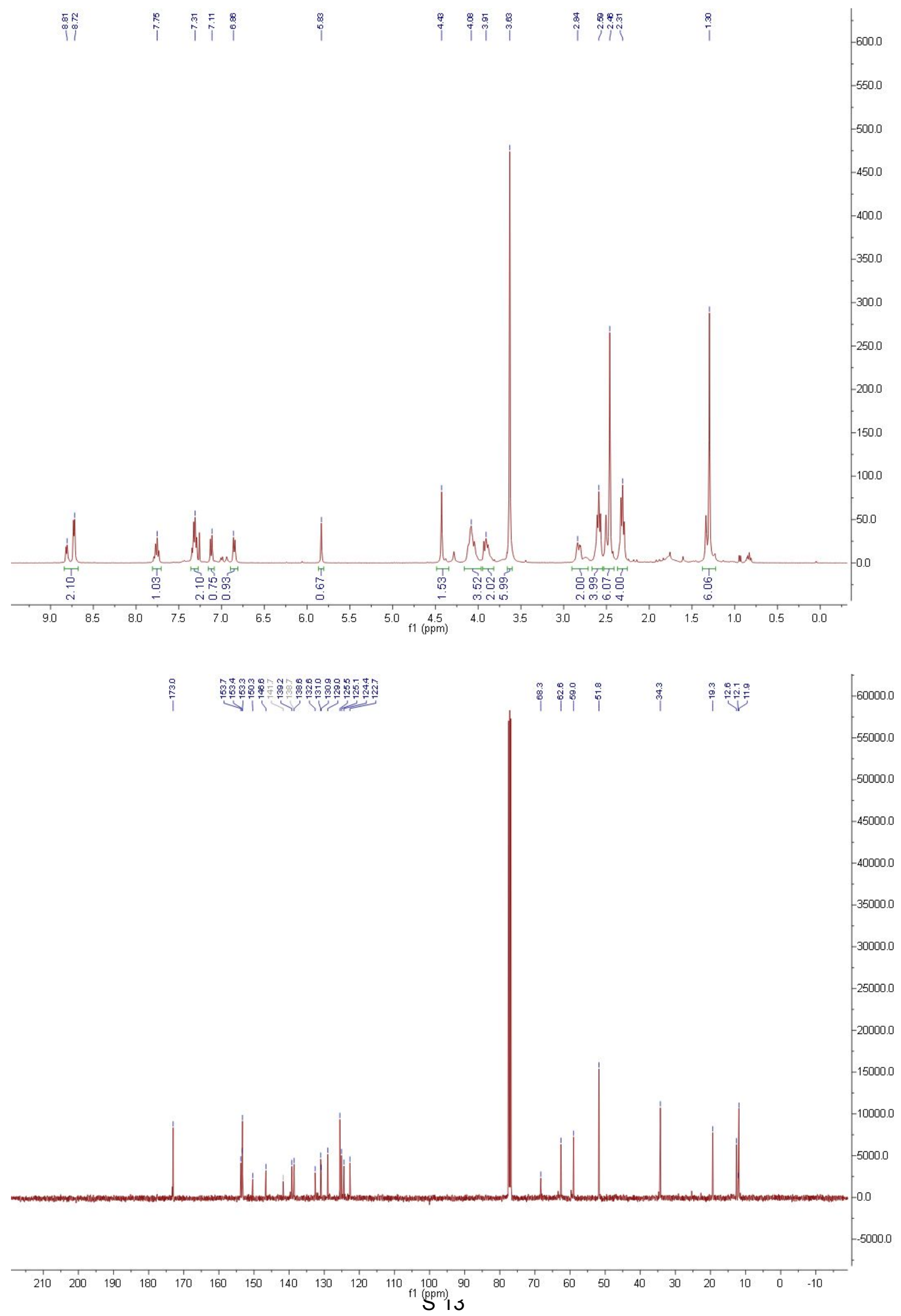
${ }^{1} \mathrm{H}$ and ${ }^{13} \mathrm{C}$ NMR Spectra of Compound COP-3E-Py'

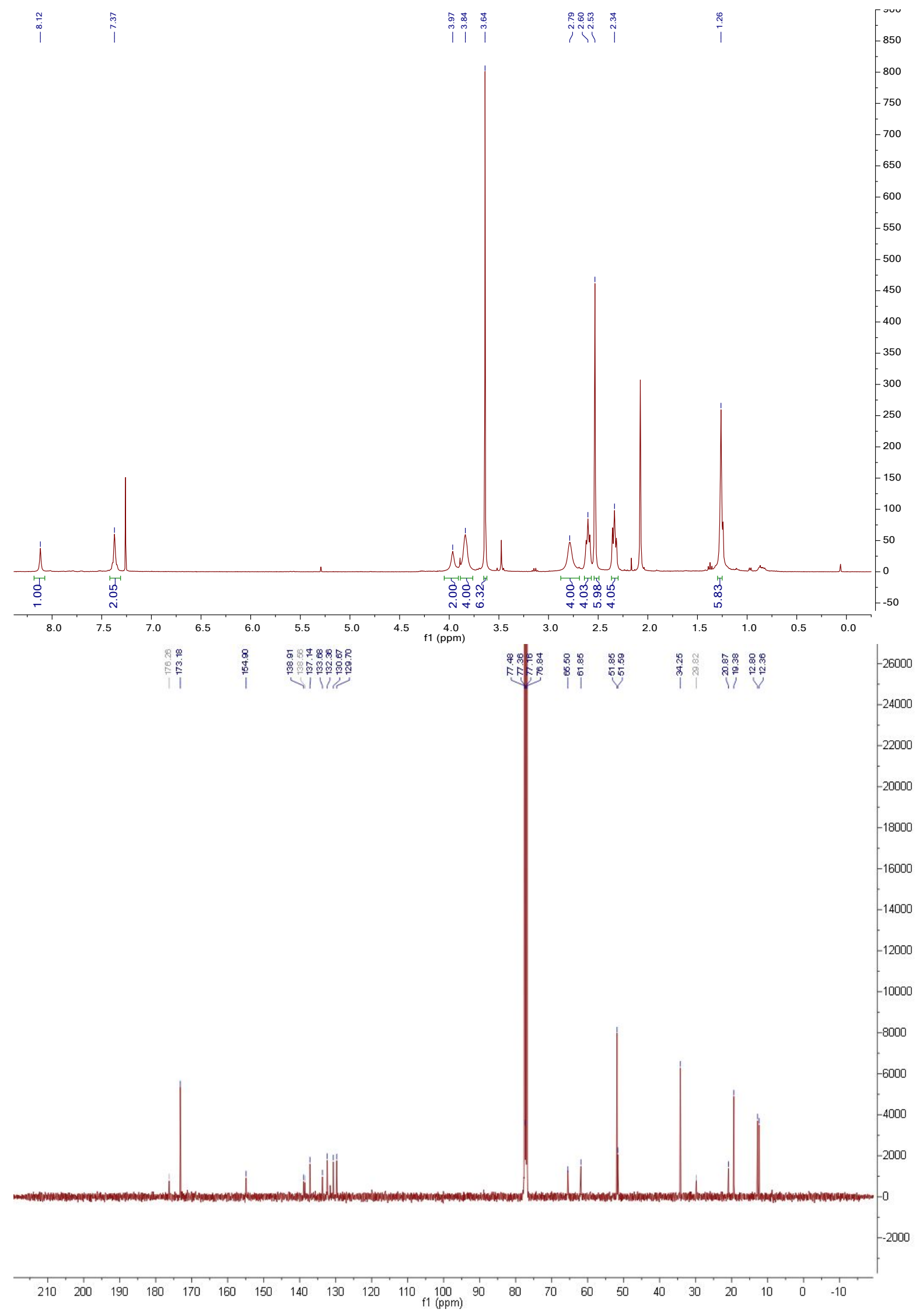




\section{References:}

[1] X. F. Zhang, J. Zhang, L. Liu, Journal of Fluorescence 2014, 24, 819-826. 